
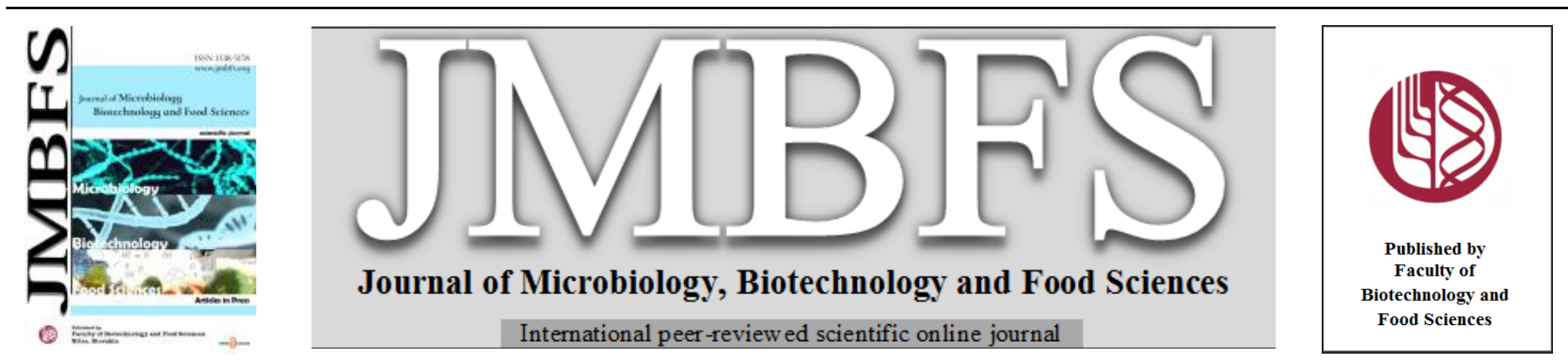

\title{
LISTERIA MONOCYTOGENES STRAIN BN3 RESPONDS TO ACYL HOMOSERINE LACTONE (AHL) BY EXPRESSION OF VIRULENCE GENE (HLYA) AND GENE RESPONSIBLE FOR BIOFILM (SRTA)
}

\author{
Milind Mohan Naik ${ }^{1}$, Sanika Naik-Samant ${ }^{* 1,2}$, Komal Salkar $^{1}$ and, Veda Manerikar ${ }^{1}$ \\ Address(es): Dr. Sanika Naik-Samant, \\ ${ }^{1}$ Department of Microbiology, Goa University, 403206, Goa, India. \\ ${ }^{2}$ Present address: Department of Biotechnology, Goa University, 403206, Goa, India. 0832-8669609246.
}

*Corresponding author: sanika2k4@gmail.com

https://doi.org/10.15414/jmbfs.1846

\section{ARTICLE INFO}

Received 21. 6. 2019

Revised 5. 8. 2021

Accepted 12. 8. 2021

Published 1. 12. 2021

Short communication

OPEN $\partial_{\text {ACCESS }}$

\begin{abstract}
Listeria monocytogenes, a foodborne pathogen and well known causative agent of listeriosis in humans that is also known to form biofilm on utensils used in the dairy industry is well studied for peptide-based Quorum sensing system (agr QS system). In the present study, we are reporting L. monocytogenes strain BN3 to respond to an acyl-homoserine lactone (AHL) by expression of virulence gene $(h l y A)$ and the gene responsible for biofilm formation (srtA) using Real-Time PCR technology. It revealed that in L. monocytogenes, hlyA gene (encodes listeriolysin O) expression increased 0.7-fold in response to $500 \mathrm{nM}$ AHL (C4-HSL treated) as compared to control. Also, in response to $500 \mathrm{nM}$ AHL, (C4-HSL treated) strain BN3 showed 27-fold up-regulation of srtA gene (encodes enzyme sortase) as compared to control. Our study confirmed the cross-talk between Gram-positive and Gram-negative bacteria since L. monocytogenes strain BN3 responds to C4-HSL, which is normally produced by Gram-negative bacteria. Here, we suggest targeting both agr based QS and AHL based QS system together in L. monocytogenes to tackle biofilm formed on milk cans in dairy industries and when treating listeria infections.
\end{abstract}

Keywords: Listeria monocytogenes, AHL, virulence gene, biofilm, real time-PCR

\section{INTRODUCTION}

Gram-positive L. monocytogenes is an emerging food-borne pathogen responsible for listeriosis in humans (Doijad et al., 2011). Various contaminated foods viz. raw milk, meat, vegetables, ready to eat foods, milking utensils, and fruit juices are the sources of infection to humans by L. monocytogenes (Doijad et al., 2010; Naik et al., 2017). This bacterium can grow in psychrophilic conditions on milk and meat kept in the refrigerator (Doijad 2014). The infections caused by L. monocytogenes show $91 \%$ hospitalization rate, $50 \%$ neonatal death rate (50 \%) and 20-30 \% death cases (Babu et al., 2017). Doijad (2014), reported that it is difficult to remove L. monocytogenes from the dairy industry clean-in-place (CIP) procedure because L. monocytogenes forms a strong biofilm on dairy utensils. The ability of L. monocytogenes to form biofilm on food surfaces and utensils is the main reason behind food-borne infection and persistence of L. monocytogenes in food industry (Oliveira et al., 2010; Doijad et al., 2015; Jamshidi and Zeinali 2019). Therefore, to control $L$. monocytogenes in food dairy industry, there is a need to control biofilm formation of L. monocytogenes on utensils used in food/dairy industry. Hemolysin gene $(h l y)$ was the first virulence gene detected in L. monocytogenes (Vazquez-Boland $\boldsymbol{e t}$ al., 2001) which encodes listeriolysin O (LLO) (Doijad $\boldsymbol{e}$ al., 2010; Doijad et al., 2011). Garandeau et al. (2002), reported that the specialized enzyme sortase (SrtA) of L. monocytogenes encoded by the srtA gene is responsible for the processing of internalin and in virulence. Doijad (2014), reported the construction of sortaseA deletion mutant (LM $\Delta s r t A)$ of wild type $L$. monocytogenes EGDe (LMWT) and found that adherence ability of mutant $\mathrm{LM} \Delta s r t A$ was decreased by 28.03 times, whereas biofilm formation potential was decreased by 7.3 times as compared to LMWT. These reports confirmed that sortase enzyme (SrtA) of L. monocytogenes are involved in biofilm formation and virulence.

Quorum sensing (QS) molecules such as Acyl homoserine lactones (AHLs) in Gram-negative bacteria and small peptides in Gram-positive bacteria (agr QS system) are well known to have a role in virulence gene expression and biofilm formation. The presence of AHL based QS system has never been reported in Gram-positive bacteria and is reported only in Gram-negative bacteria, but there is only one report saying Gram-positive bacteria Exiguobacterium sp. isolated from marine water produce C3-oxo-octanoyl homoserine lactone (OOHL) (Biswa and Doble, 2013). Qazi et al. (2006), reported that although
Staphylococcus aureus does not have the potential to produce AHL molecules, they can respond negatively to external AHL molecules. They observed that 3 oxo-C12-HSL inhibited agr QS expression and antagonized virulence gene expression in $S$. aureus. Naik et al. (2018), reported that methicillin-resistant Staphylococcus sciuri isolated from the dairy industry does not have the potential to produce AHLs but responds to AHL (C6-HSL) molecules by increased exopolysaccharide synthesis and biofilm-forming potential. L. monocytogenes strain BN3 also does not have potential to produce AHL molecules, but in our previous study we have observed that L. monocytogenes strain $\mathrm{BN} 3$ can respond to AHL molecule (C6-HSL) by enhanced biofilm formation (Naik et al., 2017). There was a gradual increase in biofilm-forming potential in L. monocytogenes strain BN3 with the gradual increase in AHL in concentration-dependent manner. In our recent study we have reported that $L$. monocytogenes strain $\mathrm{BN} 3$ responds to AHL (C6-HSL) molecules by enhanced hemolysin production in a concentration-dependent manner as revealed by sheep blood agar well diffusion assay (Naik et al., 2018). However, this study was performed using a plate assay method, which necessitated further confirmation through gene expression studies. Therefore, in the present investigation, we were interested in testing the expression of virulence genes ( $h l y A$ and $s r t A)$ and gene which has a major role in biofilm formation (srtA) in L. monocytogenes in response to AHL molecule (C4HSL) by Real-Time PCR (RT-PCR) based gene expression study. For this study we have used L. monocytogenes strain $\mathrm{BN} 3$, which was previously isolated from the utensils of the dairy industry (Naik et al., 2017).

Here, we tried to investigate the expression of $h l y A$ gene and srtA gene which encode for listeriolysin $\mathrm{O}$ (hemolysin) and sortase enzyme respectively in $L$. monocytogenes strain $\mathrm{BN} 3$ in response to 4 carbon AHL molecules (C4-HSL) (Sigma Aldrich, USA) in Brain heart infusion broth (BHI, $10 \mathrm{ml}$ ). We grew $L$. monocytogenes strain BN3 overnight (18 hrs) in BHI broth in the absence (control), and presence of $500 \mathrm{nM}$ C4-HSL (test) and then total RNA was extracted from control and AHL exposed cells. Total RNA extraction was done by isolating RNA using TRIzol reagent (TRIzol-Sigma, USA). The total RNA was treated with DNase to avoid contamination from the genomic DNA, and the total RNA was quantified using NanoDrop 2000 spectrophotometer (Thermo scientific). For the synthesis of cDNA, 500 ng total RNA was used. RNA and Hexa primer (random hexamer), were used for the first-strand cDNA synthesis by Reverse transcription using Verso cDNA synthesis kit (Thermo scientific). Conditions for converting RNA to cDNA are $42{ }^{\circ} \mathrm{C}$ for 30 min (Varma et al., 
2016). cDNA was quantified using nanodrop spectrophotometry and used as a template to study Real Time-PCR (RT-PCR) based expression of the hlyA gene and $s r t A$ gene. For gene expression study, novel primers were synthesized from the NCBI gene sequences data (primer blast) (Eurofins genomics Pvt ltd). In order to study hlyA gene expression using RT-PCR, primes used were forward primer 5'-CTTCGGCGCAATCAGTGAAG-3' and reverse primer 5' GCGCTTGCAACTGCTCTTTA-3' (Eurofins genomics Pvt ltd). In quantitative PCR (qPCR) amplification was carried out with total volume $20 \mu \mathrm{l}$ and containing $2 \mu \mathrm{l}$ of cDNA and $10 \mu \mathrm{l}$ of super mix containing SYBR Green (BioRad, USA) using Bio-Rad CFX96 system. qPCR amplification conditions were initial denaturation at $95^{\circ} \mathrm{C}$ for $5 \mathrm{~min}$, denaturation at $95^{\circ} \mathrm{C}$ for $30 \mathrm{sec}$, annealing at $55.1^{\circ} \mathrm{C}$ for $30 \mathrm{sec}$ and extension at $72{ }^{\circ} \mathrm{C}$ for $30 \mathrm{sec}$. For $s r t A$ gene expression using RT-PCR primers used were Forward primer 5' GGCGACAAGATTTACCTGACTG-3' and reverse primer 5, TAGCTCACCAACTGCGACAA-3' (Eurofins genomics Pvt ltd). qPCR conditions were initial denaturation at $95{ }^{\circ} \mathrm{C}$ for $5 \mathrm{~min}$, denaturation at $95{ }^{\circ} \mathrm{C}$ for $30 \mathrm{sec}$, annealing at $53.2{ }^{\circ} \mathrm{C}$ for $30 \mathrm{sec}$ and extension at $72{ }^{\circ} \mathrm{C}$ for $30 \mathrm{sec} .16 \mathrm{~s}$ rRNA gene was used as an internal control (Housekeeping gene) in gene expression studies for the normalization. All the experiments were done in triplicate. Also, we have done PCR amplification of hlyA gene and srtA gene directly from genomic DNA using above primers.

PCR amplification of $h l y A$ gene and $s r t A$ gene directly using genomic DNA as template confirmed presence of $h l y A$ (140 bps amplicon) gene and srtA gene (180 bps amplicon) in L. monocytogenes strain $\mathrm{BN} 3$ and specificity of novel primers synthesized in the present study.

The mRNA expression levels were normalized to that of the housekeeping gene (16s rRNA) and the results were analyzed. The $\mathrm{Ct}$ values of the test samples were calculated and the data were expressed in terms of fold change over the BN3 control sample. As seen in figure 1, the results revealed that $h l y A$ gene expression in L. monocytogenes strain BN3 exposed to $500 \mathrm{nM}$ AHL (C4-HSL treated) increased 0.7 -fold as compared to control.

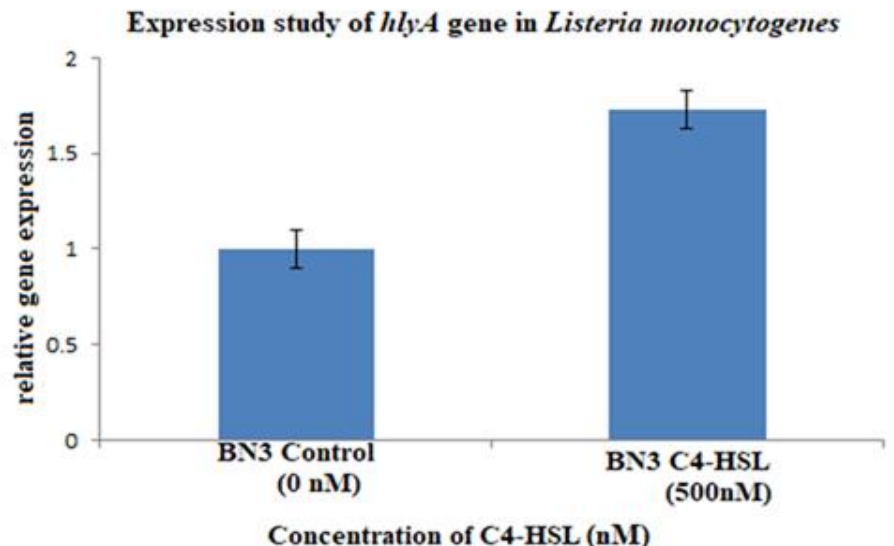

Figure 1 Expression of hlyA gene in L. monocytogenes strain BN3 in the absence (control) and presence of $500 \mathrm{nM} \mathrm{C4-HSL}$

Further, the case of the $s r t A$ gene test sample (BN3 exposed to $500 \mathrm{nM}$ C4-HSL) showed 27-fold up-regulation of srtA gene as compared to BN3-control sample (Figure 2).

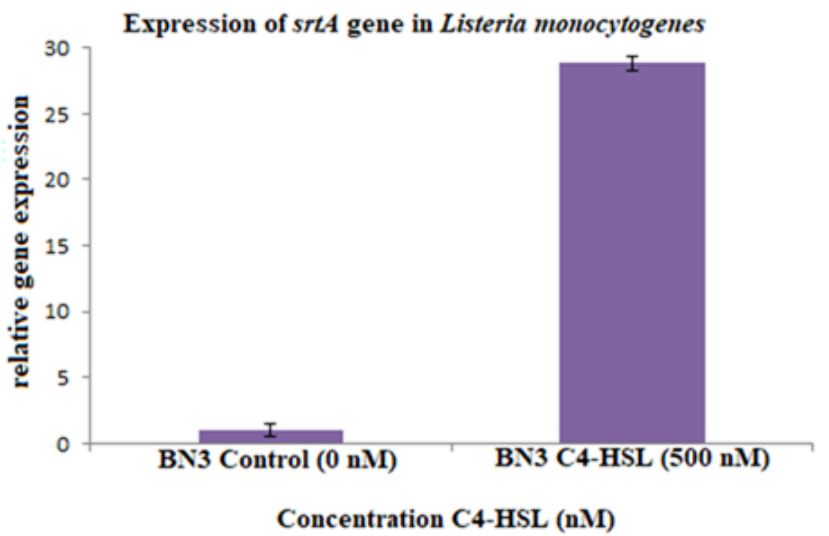

Figure 2 Expression of $s r t A$ gene in L. monocytogenes strain BN3 in the absence (control) and presence of $500 \mathrm{nM} \mathrm{C4-HSL}$

This is the first report on the response of L. monocytogenes strain $\mathrm{BN} 3$ to 4 carbon AHL (C4-HSL) by enhanced expression of hlyA and srtA genes which encode for virulence and biofilm formation. It is well known that biofilm formed on utensils used in the dairy industry is a complex biofilm and contains both Gram-negative and Gram-positive bacteria (Cherif-Antar et al., 2016). In the present investigation L. monocytogenes strain BN3 responds to C4-HSL, which is normally produced by Gram-negative bacteria. Therefore, the present study confirmed the cross-talk between Gram-positive and Gram-negative bacteria through AHL (C4-HSL) QS molecule which is not produced by Gram-positive bacteria but produced by Gram-negative bacteria. Researchers across globe target only agr QS system to control biofilm formation by L. monocytogenes on dairy industry equipment (Naik et al., 2017; Gray et al., 2013), but present study suggest targeting both $a g r$ based QS and AHL based QS system together in $L$ monocytogenes for best results. This investigation will surely help to understand the interaction between Gram-negative and Gram-positive bacteria when present in the same ecological niche. There is a lot of scope to study receptors for AHL molecules in L. monocytogenes for further understanding the communication between Gram-positive and Gram-negative bacteria.

Acknowledgment: Dr. Milind Mohan Naik is thankful to the Science and Engineering Research Board (SERB), Department of Science and Technology, Government of India, for financial support by the Young Scientist Project (File Number: YSS/2014/000258). We are also thankful to Eurofins Genomics Pvt Ltd., Bangalore for their help in real-time PCR study.

Author's Contribution All the authors have contributed equally to the work mentioned in this article.

\section{REFERENCES}

Babu, G., Balamuruganvelu S., Maulingkar S.V., Srikumar R., Reddy S. V., Senthamizhan, V.S. (2017). Incidence rate and antibiotic susceptibility pattern of Listeria species in high risk groups. National Journal of Laboratory Medicine 6(2), MO11-MO15. http://dx.doi.org/10.7860/NJLM/2017/25461:2224

Biswa, P., Doble, M. (2013). Production of acylated homoserine lactone by Gram-positive bacteria isolated from marine water. FEMS Microbiol Lett, 343 34-41. http://dx.doi.org/10.1111/1574-6968.12123

Cherif-Antar, A., Moussa-Boudjemâa, B., Didouh, N., Medjahdi, K., Mayo, B. Flórez, A. B. (2016). Diversity and biofilm-forming capability of bacteria recovered from stainless steel pipes of a milk-processing dairy plant. Dairy Sci \& Technol, 96, 27-38. https://doi.org/10.1007/s13594-015-0235-4

Doijad, S., Barbuddhe, S. B., Garg, S., Kalekar, S., Rodrigues, J., D’Costa D., Bhosle, S., Chakraborty, T. (2011). Incidence and genetic variability of Listeria species from three milk processing plants. Food Control, 22, 1900-1904

Doijad, S. P., Vaidya, V., Garg, S., Kalekar, S., Rodrigues, J., D'Costa D. Bhosle, S., Barbuddhe, S. (2010). Isolation and characterization of Listeria species from raw and processed meats. J Veter Pub Health, 8, 83-88.

Doijad, S. P. (2014). Biofilm forming ability and disinfectant resistance of Listeria species from food and food processing units. (Doctoral thesis), Goa University, Goa.

Doijad, S. P., Barbuddhe, S. B., Garg, S., Poharkar, K. V., Kalorey, D. R., Kurkure, N.V., Rawool, D.B., Chakraborty, T. (2015). Biofilm-forming abilities of L. monocytogenes serotypes isolated from different sources. PLoS One, 10, 114. https://doi.org/10.1371/journal.pone.0137046

Garandeau, C., Réglier-Poupet, H., Dubail, I., Beretti, J. L., Berche, P., Charbit, A. (2002). The sortase SrtA of L. monocytogenesis involved in processing of internalin and in virulence. Infect Immun, 70, 1382-90. http://dx.doi.org/10.1128/IAI.70.3.1382-1390.2002

Gray, B., Hall, P., Gresham, H. (2013). Targeting agr- and agr-like quorum sensing systems for development of common therapeutics to treat multiple Gram positive bacterial infections. Sensors, 13, 5130-5166. http://dx.doi.org/10.3390/s130405130

Jamshidi, A., Zeinali, T. (2019). Significance and characteristics of $L$ monocytogenesin poultry products. Int J Food Sci, Article ID 7835253 https://doi.org/10.1155/2019/7835253.

Naik, M. M., Bhangui, P., Bhat, C. (2017). The first report on L. monocytogenes producing siderophores and responds positively to $N$-acyl homoserine lactone (AHL) molecules by enhanced biofilm formation. Arch Microbiol, 199, 14091415. http://dx.doi.org/ 10.1007/s00203-017-1416-8

Naik, M. M., Naik, S. P., Dubey, S. K., Bhat, C., Charya, L.S. (2018). Enhanced exopolysaccharide production and biofilm-forming ability in methicillin-resistan Staphylococcus sciuri isolated from dairy in response to Acyl homoserine lactone (AHL). J Food Sci Technol, 55, 2087-2094. http://dx.doi.org/10.1007/s13197. 018-3123-0

Naik, M. M., Prabhu, M. S., Manerikar, V. (2018). The first report on Acyl homoserine lactone (AHL) enhanced expression of virulence factor, hemolysin in Gram-positive, L. monocytogenes strain BN3 isolated from dairy industry. Indian J Dairy Sci, 71, 313-318. http://dx.doi.org/10.1007/s00203-017-1416-8

Oliveira, M. M. M., Brugnera, D. F., Alves, E., Piccoli, R. H. (2010). Biofilm formation by L. monocytogenes on stainless steel surface and biotransfer potential. Braz J Microbiol, 41, 97-106. http://dx.doi.org/10.1590/S1517$\underline{838220100001000016}$ 
Qazi, S., Middlenton, B., Muharram, S. H., Cockayne, A., Hill, P., O'shea, P., Chhabra, S.R., Cámara, M., Williams, P. (2006). N-Acylhomoserine lactones antagonize virulence gene expression and quorum sensing in Staphylococcus aureus. Infect Immun, 74, 910-919. http://dx.doi.org/10.1128/IAI.74.2.910$\underline{919.2006}$

Varma, S. R., Sivaprakasam, T. O., Mishra, A., Kumar, L. M. S., Prakash, N. S. Prabhu, S., Ramkrishnan, S. (2016). Protective effects of Triphala on dermal fibroblasts and human keratinocytes. PLoS One, https://doi.org/10.1371/journal.pone.0145921

Vázquez-Boland, J. A., Kuhn, M., Berche, P., Chakraborty, T., DomínguezBernal, G., Goebel, W., González-Zorn, B., Wehland, J., Kreft, J. (2001). Listeria pathogenesis and molecular virulence determinants. Clin Microbiol Rev, 14, 584640. http://dx.doi.org/10.1128/CMR.14.3.584-640.2001 